\title{
A study of orthorhombic phases in aluminium-transition metal alloys*
}

\author{
T R ANANTHARAMAN \\ Metals and Alloys Group, National Physical Laboratory, Dr K S Krishnan Road, New Delhi 110012 , India \\ MS received 12 February 1999; revised 19 June 1999
}

\begin{abstract}
In recent decades some complex crystalline phases, as also many rational approximants to quasicrystalline phases with rather large unit cells, have been reported with orthorhombic symmetry in aluminium-transition metal (AI-TM) alloys. Furthermore, quite a few quasicrystalline phases, icosahedral as well as decagonal, forming in Al-TM alloys on normal or rapid solidification have been interpreted during the last decade as multiply-twinned orthorhombic crystals growing as superstructures of an orthorhombic cell that forms through welding in three perpendicular directions in the liquid state of 13-atom icosahedral clusters.

Following exemplification of this new approach to quasicrystals based on the analysis of the Debye-Scherrer diffraction data from the comparatively defect-free Al-Cu-Fe icosahedral phase, the three types of orthorhombic phases in aluminium-rich Al-TM alloys, numbering 36 in all, have been examined as icosahedral cluster compounds nucleating from icosahedral atomic clusters present in the molten alloys. A detailed analysis of their lattice parameters supports the postulate that all such phases can be viewed as complex and, occasionally, as very large superstructures of a small basic orthorhombic cell.
\end{abstract}

Keywords. Aluminium alloys; orthorhombic structure; icosahedral clusters.

\section{Introduction}

The occurrence of a new species of alloy phases, icosahedral cluster compounds, was postulated recently (Anantharaman 1998a). The essential pre-requisites for the nucleation and growth of such compounds from 13-atom icosahedral clusters in the liquid alloys were enumerated with special reference to aluminium-transition metal (Al-TM) alloys. Three distinct modes of growth were identified depending on the nature and content of the solute atoms, their electronic structures, and their interactions among themselves and with aluminium atoms.

This new concept of icosahedral cluster compounds has been welcomed as a fundamental model (Steurer 1998), and as a designation applicable to all crystalline approximants to quasicrystals (Kuo 1998). Actually it marks a certain culmination to the determined efforts on the part of a few far sighted scientists spread over half a century to understand and pinpoint the precise role of 13-atom icosahedral clusters supposed to be present in the liquid state.

Pauling (1947) first pointed out that the close packing of spherical atoms of equal size having coordination number 12 , as in a cubic or hexagonal close packing (A1 or A3 structures), does not represent the closest possible packing. The latter is obtained 'by grouping twelve spheres at the corners of a regular trigonal icosahedron about a smaller sphere'. Frank (1952), while discussing

*Dedicated to the dearly cherished memory of Professor Sir William Hume-Rothery F.R.S. (1899-1968) in his birth centenary year. supercooling of liquids, and Bernal (1959), while dealing with amorphous structures, also came to the same conclusion. Later, Hume-Rothery and Anderson (1960) put forward the concept of pentagonal chains of atoms formed by vertex joining of the 13-atom Frank units to explain the occurrence of eutectics at rather unusual compositions in binary alloy systems. Subsequently, the possible role of such pentagonal chains of atoms in the formation of metallic glasses on rapid solidification of aluminium-rich Al-TM alloys was discussed by Anantharaman et al (1977).

Following the advent of quasicrystals (Schechtman et al 1984) and the fast as well as fascinating development of quasicrystallography (see Steurer 1996), the promise of a unified model for icosahedral motifs in glasses, quasicrystals, and complex crystals started attracting attention (Anantharaman 1987; Widom 1987). The golden thread running through the numerous and diverse Al-TM alloy phases was eventually identified as the icosahedral atomic cluster present in the molten alloys (Anantharaman 1994a). From here it was just another logical step to postulate a new species of intermetallic phases, viz. icosahedral cluster compounds, different from the stoichiometric chemical compounds as well as from the Hume-Rothery electron compounds.

According to this new concept, the formation of orthorhombic or related crystalline phases through one of the three proposed modes of growth may be expected in Al-TM alloys in the composition range $\mathrm{Al}_{11} \mathrm{TM}_{2}$ to $\mathrm{Al}_{8} \mathrm{TM}_{5}$, i.e. with roughly 15 to 40 at $\%$ of one or more transition metals in the alloys (Anantharaman 1998a). Initially, the ordered 13-atom clusters or basic hyperatoms 
join and weld themselves with atom sharing in all the three directions to generate an orthorhombic cell, that can be viewed as a distorted icosahedron that still retains some of its original symmetry. Subsequently, the growth into big superstructures from this idealized building block occurs through complex ordering of the dissimilar atoms and also vacancies, leading to orthorhombic or related rhombohedral, hexagonal, and monoclinic structures.

In this paper, all available reliable data on the three types of orthorhombic phases in Al-TM alloys, numbering 36 in all, and containing 60 to 85 at\% of aluminium, has been examined to ascertain whether these phases belong to the category of icosahedral cluster compounds, growing from icosahedral atomic cluster in the concerned molten alloys.

\section{Emergence of the orthorhombic cell}

In order to appreciate the analytical approach underlying the present study, it is essential to follow step by step, along with visualization in three dimensions, how an orthorhombic cell emerges through the coming together of 13-atom icosahedral clusters. Table 1 gives the coordinates of atoms located at the 12 vertices of an ideal icosahedron, as given in geometry books, with the origin at the body centre and the edge length taken as unity. When such clusters, each with a TM atom added at the body centre, join along the vertex and form pentagonal chains with (-1-5-1-5-1-5-)-sequence of atoms (Hume-Rothery and Anderson 1960), appropriate con-

Table 1. Coordinates of atoms located at the 12 vertices of an ideal icosahedron with the origin at body centre, as for 13 th atom; and the edge length taken as unity.

\begin{tabular}{|c|c|c|c|}
\hline \multirow{2}{*}{$\begin{array}{l}\text { Atom } \\
\text { no. }\end{array}$} & \multicolumn{3}{|c|}{ Axis } \\
\hline & $x$ & $y$ & $z$ \\
\hline 1 & 0.000 & 0.951 & 0.000 \\
\hline 2 & 0.000 & 0.425 & -0.851 \\
\hline 3 & -0.809 & 0.425 & -0.263 \\
\hline 4 & -0.500 & 0.425 & 0.688 \\
\hline 5 & 0.500 & 0.425 & 0.688 \\
\hline 6 & 0.809 & 0.425 & -0.263 \\
\hline 7 & 0.500 & -0.425 & -0.688 \\
\hline 8 & -0.500 & -0.425 & -0.688 \\
\hline 9 & -0.809 & -0.425 & 0.263 \\
\hline 10 & 0.000 & -0.425 & 0.851 \\
\hline 11 & 0.809 & -0.425 & 0.263 \\
\hline 12 & 0.000 & -0.951 & 0.000 \\
\hline 13 & 0.000 & 0.000 & 0.000 \\
\hline
\end{tabular}

Note: When vertex joining of icosahedral atomic clusters takes place and pentagonal chains with $-1-5-1-5-1-5-$ sequence form in the molten alloys, some contraction is to be expected along the $y$ axis and the coordinates of atoms nos 1 and 12 may well become $0.850(2 \times 0.425)$ and $-0.850(2 \times-0.425)$ respectively, while other coordinates in the $x$ and $z$ axis register some expansion. tractions may be expected along the $y$ axis, with symmetry and balance of electrostatic forces shaping the resulting chain (see note below table 1). In fact, further changes or distortions in the shape of the icosahedral cluster will occur, because of the smaller size of the solute TM atoms and the expected contraction of the Al-TM atomic bond (Gong and Kumar 1995).

Table 2 presents the atomic positions and coordinates in a vertex-joined pentagonal chain, as also the actual distances along the three axes for an average edge length i.e. interatomic distance, of $2.5 \AA$. In arriving at this average value, one has to appreciate the fact that there is generally a wide scatter in the values of Al-TM interatomic distances, as measured and reported for different Al-TM crystalline phases. To cite a recent example, the detailed examination (Kreiner and Franzen 1997) of the crystal structure of $\lambda-\mathrm{Al}_{4} \mathrm{Mn}$ with 586 positions located in the unit cell has revealed a large number of $\mathrm{Al}-\mathrm{Mn}$ interatomic distances ranging from $2.362 \AA$ to $2.949 \AA$. Interestingly, this investigation has also shown that 102 positions of the $104 \mathrm{Mn}$ positions in this crystalline phase are characterized by icosahedral coordination.

A cursory glance at the $x_{2}, y_{2}$, and $z_{2}$ coordinates in table 2 reveals the significant fact that a large number of these coordinates include values of $0.00,0.25,0.50$ and 0.75 even before the linkage, with the inevitable minor atomic shifts, of the icosahedral clusters along the $x$ and $z$ axes. The approximate dimensions of the unit cell encompassing this idealized, albeit actually distorted, icosahedral cluster with the mean interatomic distance of $2.50 \AA$ can now be computed as $a^{\prime}=4.046 \AA$, $b^{\prime}=4.250 \AA$, and $c^{\prime}=4.254 \AA$. The symmetry of this cell is orthorhombic, although it is easy enough to visualize possible changes in symmetry to cubic, tetragonal, hexagonal, rhombohedral or monoclinic, through small atom movements leading to further changes in the icosahedral shape. Furthermore, as the volume of the orthorhombic cell is obviously more than that of the icosahedral cluster it encompasses, one can visualize and allow for some additional re-alignment or re-positioning in the lattice of the edge and face atoms (nos 2-6 and $7-11$ in table 2) in the liquid state which is characterized by greater atomic mobility than the solid state.

Figures 1 and 2 bring out graphically the emergence of the orthorhombic cell through the joining and welding together of the vertex, edge and face atoms, 12 in number, in three mutually perpendicular directions. Such a cell can be assigned the space group $P_{m m m}$ (no. 47) and may contain a maximum of 7 atoms with all the 12 atoms of the icosahedral vertices getting equally shared in the joining process and the single body centre atom continuing within the body despite the distortions in the icosahedral shape. Following a detailed study of rational approximants to decagonal phases, it was shown (Anantharaman 1994a) that the $c^{\prime}$ parameter can in fact be halved to $2 \cdot 127 \AA$ and the actual dimensions of this smaller basic 
orthorhombic cell with two possible variants in atomic positions (figure 3 ) can be arrived at for any quasicrystalline phase on the basis of its Debye-Scherrer pattern.

In passing, it is of interest to note that a theoretical study by Niizeki (1992) of the possible space groups has identified $P_{m m m}$ as a possibility along with $C_{m m m}$ and $I_{m m m}$ for orthorhombic approximants of icosahedral phases.

\section{Application to $\mathrm{Al}-\mathrm{Cu}-\mathrm{Fe}$ icosahedral phase}

Among dozens of documented icosahedral phases, the $i$-Al-Cu-Fe phase is well known for its thermodynamic stability showing absence of imperfections like phason strain, and extremely sharp X-ray and neutron reflections. Here, as an illustration, the neutron reflections (figure 4) from a rapidly solidified $\mathrm{Al}_{65} \mathrm{Cu}_{20} \mathrm{Fe}_{15}$-icosahedral phase are analysed in three stages. The basic orthorhombic cell is first identified, the dimensions of the superstructure constituting $i-\mathrm{Al}-\mathrm{Cu}-\mathrm{Fe}$ are then computed, and finally the observed interplaner distances (table 3 ) are compared with the calculated values. The neutron diffraction data used here was made available by Dr C Janot and his coworkers (Institute Laue-Langevin, Grenoble, France).

As postulated by the author in several papers (Anantharaman $1989,1993,1994 a, b)$ all icosahedral, decagonal and rational approximant phases can be viewed as orthorhombic crystals with large unit cells, which are only superstructures of the small, basic orthorhombic cell, built through complex ordering of aluminium atoms, and transition metal atoms and vacancies. While the dimensions of the superstructure discussed in the above paragraph were arrived at for the idealized basic cell, the actual values of $a^{\prime}, b^{\prime}$, and $c^{\prime}$ will depend, in any particular case, on the nature and percentage of transition metals in the alloy. These values can however be arrived at from a careful study of the X-ray or neutron reflections from the alloy. The lattice parameters, $a, b$, and $c$ of the orthorhombic phase under study are actually $m a^{\prime}, n b^{\prime}$, and $o c^{\prime}$ respectively, where $m, n$, and $o$ are integers. The values of $m$, $n$, and $o$ can be established through careful analysis of the positions of the few strong and medium reflections on the one hand, and the many weak and very weak low-angle reflections on the other, on the basis of the concerned Debye-Scherrer pattern. As stressed earlier (Anantharaman 1994b), the weak reflections, at very low Bragg angles, offer important clues regarding the actual size of the concerned orthorhombic superstructure.

In case of the $i-\mathrm{Al}-\mathrm{Cu}-\mathrm{Fe}$ phase, by following the approach described above the following values could be arrived at:

$$
\begin{array}{ll}
a=4 a^{\prime}=1.6309 \mathrm{~nm} ; & a^{\prime}=0.4077 \mathrm{~nm} \\
b=4 b^{\prime}=1.7149 \mathrm{~nm} ; & b^{\prime}=0.4287 \mathrm{~nm} \\
c=6 c^{\prime}=1.5119 \mathrm{~nm} ; & c^{\prime}=0.2520 \mathrm{~nm}
\end{array}
$$

Obviously, there is considerable expansion along the $z$ axis, resulting in an appreciable increase of the $c^{\prime}$ parameter vis-a-vis the value arrived at above for the idealized basic cell. Such an expansion has been noted by the author in case of all icosahedral and decagonal phases studied by him (see table 4 ).

Table 2. Data on icosahedral atomic cluster in a vertex-joined pentagonal - 1-5-1-5-1- chain [derived from table 1 for an edge length i.e. average interatomic distance, of $2.50 \AA, x_{1}, y_{1}$, and $z_{1}$ are atomic coordinates with

\begin{tabular}{|c|c|c|c|c|c|c|c|c|c|}
\hline \multirow[b]{2}{*}{$\begin{array}{l}\text { Atom } \\
\text { no. }\end{array}$} & \multicolumn{3}{|c|}{ Along $x$ axis } & \multicolumn{3}{|c|}{ Along $y$ axis } & \multicolumn{3}{|c|}{ Along $z$ axis } \\
\hline & $\begin{array}{c}\text { Distance } \\
(\AA)\end{array}$ & $x_{1}$ & $x_{2}$ & $\begin{array}{c}\text { Distance } \\
(\AA)\end{array}$ & $y_{1}$ & $y_{2}$ & $\begin{array}{c}\text { Distance } \\
(\AA)\end{array}$ & $z_{1}$ & $z_{2}$ \\
\hline 1 & 0.000 & 0.00 & 0.50 & $2 \cdot 125$ & 0.50 & 1.00 & 0.000 & 0.00 & $0 \cdot 50$ \\
\hline 2 & 0.000 & 0.00 & 0.50 & 1.063 & 0.25 & 0.75 & $-2 \cdot 127$ & -0.50 & 0.00 \\
\hline 3 & -2.023 & -0.50 & 0.00 & 1.063 & 0.25 & 0.75 & -0.657 & -0.15 & 0.35 \\
\hline 4 & $-1 \cdot 250$ & -0.31 & $0 \cdot 19$ & 1.063 & 0.25 & 0.75 & 1.721 & 0.40 & 0.90 \\
\hline 5 & 1.250 & 0.31 & 0.81 & 1.063 & 0.25 & 0.75 & 1.721 & 0.40 & 0.90 \\
\hline 6 & $2 \cdot 023$ & 0.50 & 1.00 & 1.063 & 0.25 & 0.75 & -0.657 & -0.15 & 0.35 \\
\hline 7 & $1 \cdot 250$ & 0.31 & 0.81 & -1.063 & -0.25 & 0.25 & -1.721 & -0.40 & 0.10 \\
\hline 8 & $-1 \cdot 250$ & -0.31 & $0 \cdot 19$ & -1.063 & -0.25 & 0.25 & -1.721 & -0.40 & $0 \cdot 10$ \\
\hline 9 & $-2 \cdot 023$ & -0.50 & 0.00 & -1.063 & -0.25 & 0.25 & 0.657 & 0.15 & 0.65 \\
\hline 10 & 0.000 & 0.00 & 0.50 & -1.063 & -0.25 & 0.25 & $2 \cdot 127$ & 0.50 & 1.00 \\
\hline 11 & 2.023 & 0.50 & 1.00 & -1.063 & -0.25 & 0.25 & 0.657 & 0.15 & 0.65 \\
\hline 12 & 0.000 & 0.00 & 0.50 & $-2 \cdot 125$ & -0.50 & 0.00 & 0.000 & 0.00 & 0.50 \\
\hline 13 & 0.000 & 0.00 & 0.50 & 0.000 & 0.00 & 0.50 & 0.000 & 0.00 & 0.50 \\
\hline
\end{tabular}
atom 13 at the origin i.e. $(0,0,0) ; x_{2}, y_{2}$ and $z_{2}$ are atomic coordinates with atom 13 at the body centre i.e. $0 \cdot 5,0.5$, $0 \cdot 50]$.

Note: Along $y$ axis, the coordinates for atom nos 1 and 12 are taken here as 0.850 and -0.850 , respectively, as indicated in the note below table 1 . Thus the minimum dimensions of the basic cell encompassing an idealized vertex-joined icosahedral cluster with an average interatomic distance of $2.50 \AA$ may be expected to be: $a=2 \times 2.023=4.046 \AA ; b=2 \times 2.125=4.250 \AA$ and $c=2 \times 2.127=4.254 \AA$, without considering the inevitable movements of the atoms to fit into a Bravais lattice. 
Table 3 lists the calculated and observed interplaner distances $\left(d_{\text {cal }}\right.$ and $\left.d_{\mathrm{obs}}\right)$ for no less than 80 strong, medium, weak, and very weak Debye-Scherrer reflections from $\mathrm{Al}_{65} \mathrm{Cu}_{20} \mathrm{Fe}_{15}$ icosahedral phase, together with the observed relative integrated intensities $\left(I_{\mathrm{obs}}\right)$. The Miller indices are given as $(h, k, l)$ for the superstructure and, wherever possible, as $\left(h^{\prime}, k^{\prime}, l^{\prime}\right)$ for the basic orthorhombic cell as well (see also figure 4). The agreement between $d_{\text {cal }}$ and $d_{\text {obs }}$ is extremely good, the strong reflections have convincing Miller indices and the high angle reflections (nos 69 to 80 in table 3), as also all strong reflections (nos $21,24,42,54$, etc in table 3 ), can be assigned indices pertaining to the small basic cell as well.

The halved basic cell can have, according to our approach, a maximum of 3.5 atoms, which means that the

(9)

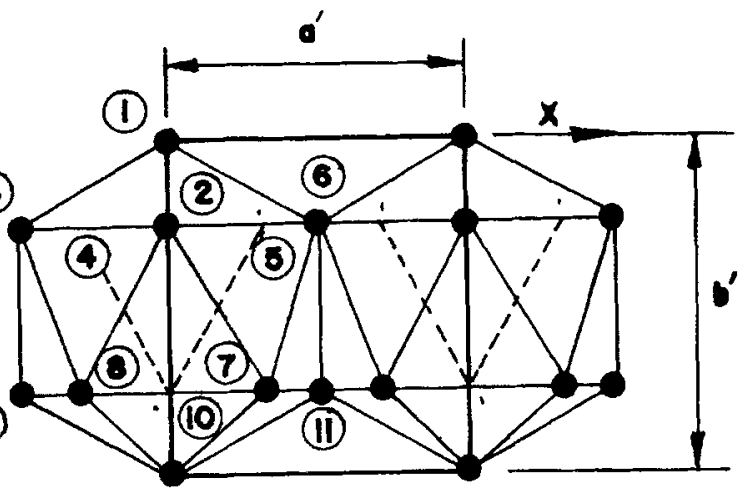

(12)

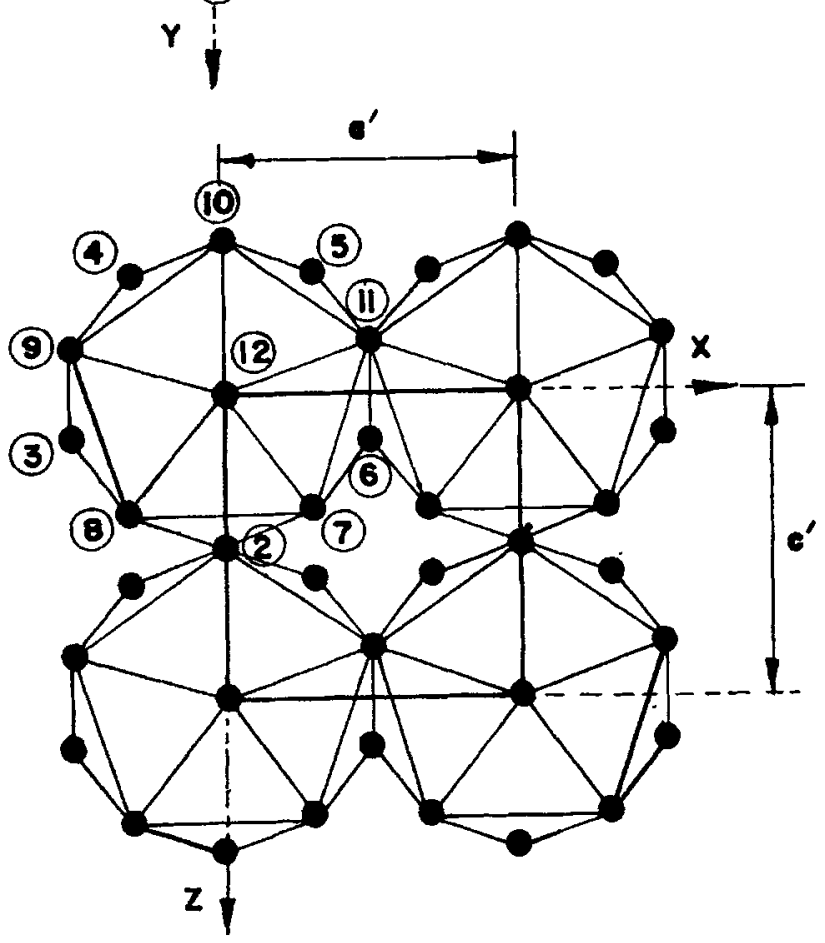

Figure 1. Location of atoms in icosahedral clusters before joining together to form the orthorhombic cell. (13th atom of body centre not shown; visible atoms shown with solid markers; invisible atoms at back numbered, but not marked; in the lower diagram atom no. 1 is invisible and coincides with atom no. 12). actual number may just be 3 in any individual unit, but the superstructure may have fractional values close to 3 atoms/unit, with vacancies playing a significant role in the overall distribution of atoms. The atomic positions in figure 3 may now be examined from the point of view of the two possible variants of the basic cell, each with a maximum of four effective atoms. Clearly enough, vacancies become a necessity to enable the changeover in all the three directions from one variant to another in adjacent units of the superstructure made up of $(m \times n \times o)$ units, which work out to $4 \times 4 \times 6=96$ for the $i-\mathrm{Al}-\mathrm{Cu}-\mathrm{Fe}$ phase. Incidentally, Chidambaram et al (1993) looked for vacancy defects in samples of $i$-Al-Cu$\mathrm{Fe}$, using positron lifetime measurements, and observed very high vacancy concentrations in this quasicrystalline phase, in fact about three orders of magnitude more than those observed in crystalline metals and alloy phases.

The density of rapidly solidified $i$ - $\mathrm{Al}_{65} \mathrm{Cu}_{20} \mathrm{Fe}_{15}$ was first reported by Calvayrac et al (1990) as $4.57 \pm 0.06 \mathrm{gcm}^{-3}$ and was measured recently by the author as $4.67 \pm$ $0.06 \mathrm{gcm}^{-3}$ by the immersion technique. Although such density values cannot be considered very reliable, it is significant that the number of atoms in the basic cell, as computed from the lattice parameters of $i$-Al-Cu-Fe, works out to 2.98 and 3.04 for the two mean values. One may thus be justified in drawing the conclusion that the effective number of atoms is exactly 3 in the basic cell and slightly lower, but close to 3 , in the superstructures, because of vacancies in the lattice.

\section{Analysis of structural data}

Taking into account the earlier analysis (Anantharaman 1993) of icosahedral $\mathrm{Al}_{80} \mathrm{Mn}_{20}$ and decagonal $\mathrm{Al}_{75} \mathrm{Mn}_{25}$

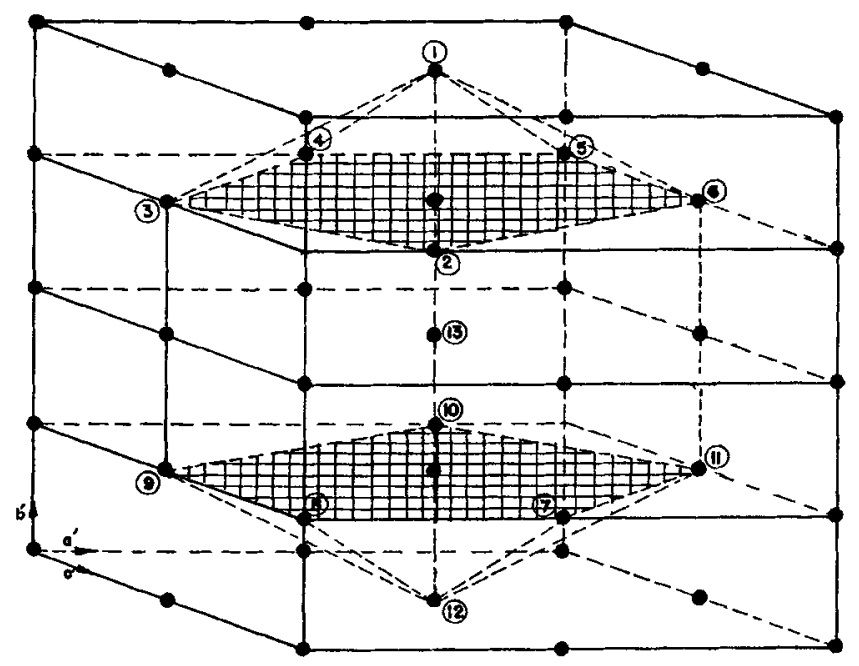

Figure 2. Location of atoms of the distorted icosahedral atomic cluster in the orthorhombic cell. (Numbering of atoms as in figure 1; atomic coordinates, as in table 2, but slightly altered and idealized.) 


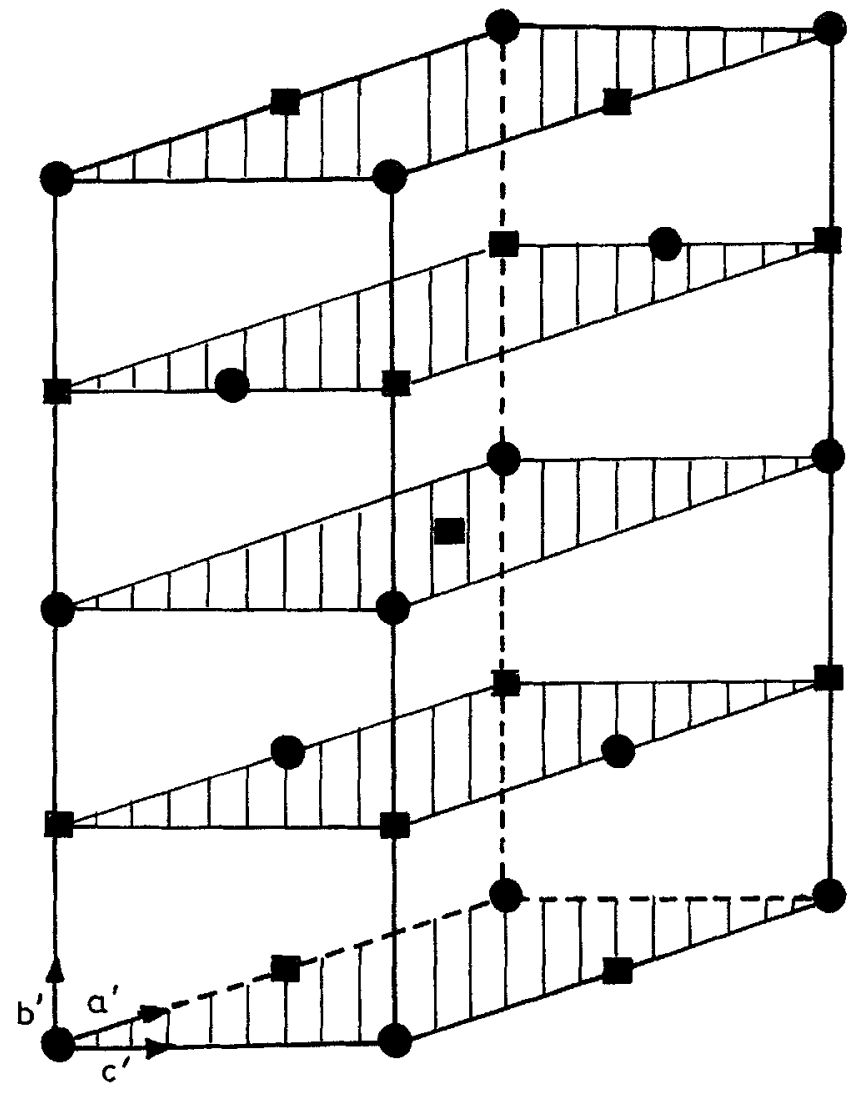

Figure 3. Sketch of the basic orthorhombic cell with somewhat idealized atomic positions in two variants $(\bullet$, variant 1 ; $\mathbf{\square}$, variant 2). (Here the $c$ parameter in figure 2 has been halved.) phases, it is now possible to compare the dimensions of three different basic cells as:

$i-\mathrm{Al}_{80} \mathrm{Mn}_{20} \quad: a^{\prime}=0.414 \mathrm{~nm}, b^{\prime}=0.435 \mathrm{~nm}, c^{\prime}=0.255 \mathrm{~nm}$. $d-\mathrm{Al}_{75} \mathrm{Mn}_{25} \quad: a^{\prime}=0.411 \mathrm{~nm}, b^{\prime}=0.418 \mathrm{~nm}, c^{\prime}=0.254 \mathrm{~nm}$. $i-\mathrm{Al}_{65} \mathrm{Cu}_{20} \mathrm{Fe}_{15}: a^{\prime}=0.408 \mathrm{~nm}, b^{\prime}=0.429 \mathrm{~nm}, c^{\prime}=0.252 \mathrm{~nm}$.

Starting with pure $\mathrm{Al}$, where we have an fcc unit cell with $a=b=c=0.405 \mathrm{~nm}$ and 4 atoms, the volume of the unit cell works out to $0.405^{3}$, i.e. $0.066 \mathrm{~nm}^{3}$; and the atomic volume to $0.066 \div 4=0.0165 \mathrm{~nm}^{3}$. As for the three basic orthorhombic cells with 3 atoms in each, the following atomic volumes emerge from the cell dimensions:

$$
\begin{array}{ll}
i-\mathrm{Al}_{80} \mathrm{Mn}_{20} & : 0.0153 \mathrm{~nm}^{3} \\
d-\mathrm{Al}_{75} \mathrm{Mn}_{25} & : 0.0145 \mathrm{~nm}^{3} \\
i-\mathrm{Al}_{65} \mathrm{Cu}_{20} \mathrm{Fe}_{15} & : 0.0147 \mathrm{~nm}^{3}
\end{array}
$$

The smaller atomic volumes for Al-TM phases are on expected lines, keeping in mind the smaller size of the solute TM atoms and the predicted contraction of the Al-TM atomic bond (Gong and Kumar 1995). It is quite significant and highly encouraging for the concepts underlying this paper that the atomic volumes of $\lambda-\mathrm{Al}_{4} \mathrm{Mn}$ and $\mathrm{Al}_{28} \mathrm{Mn}_{11}$ crystalline phases have been computed as $0.0152 \mathrm{~nm}^{3}$ and $0.0148 \mathrm{~nm}^{3}$, respectively, on the basis of single crystal X-ray studies (Shi et al 1994; Kreiner and Franzen 1997).

It is appropriate to record here that in the model developed by the author, the inevitable minor expansions,

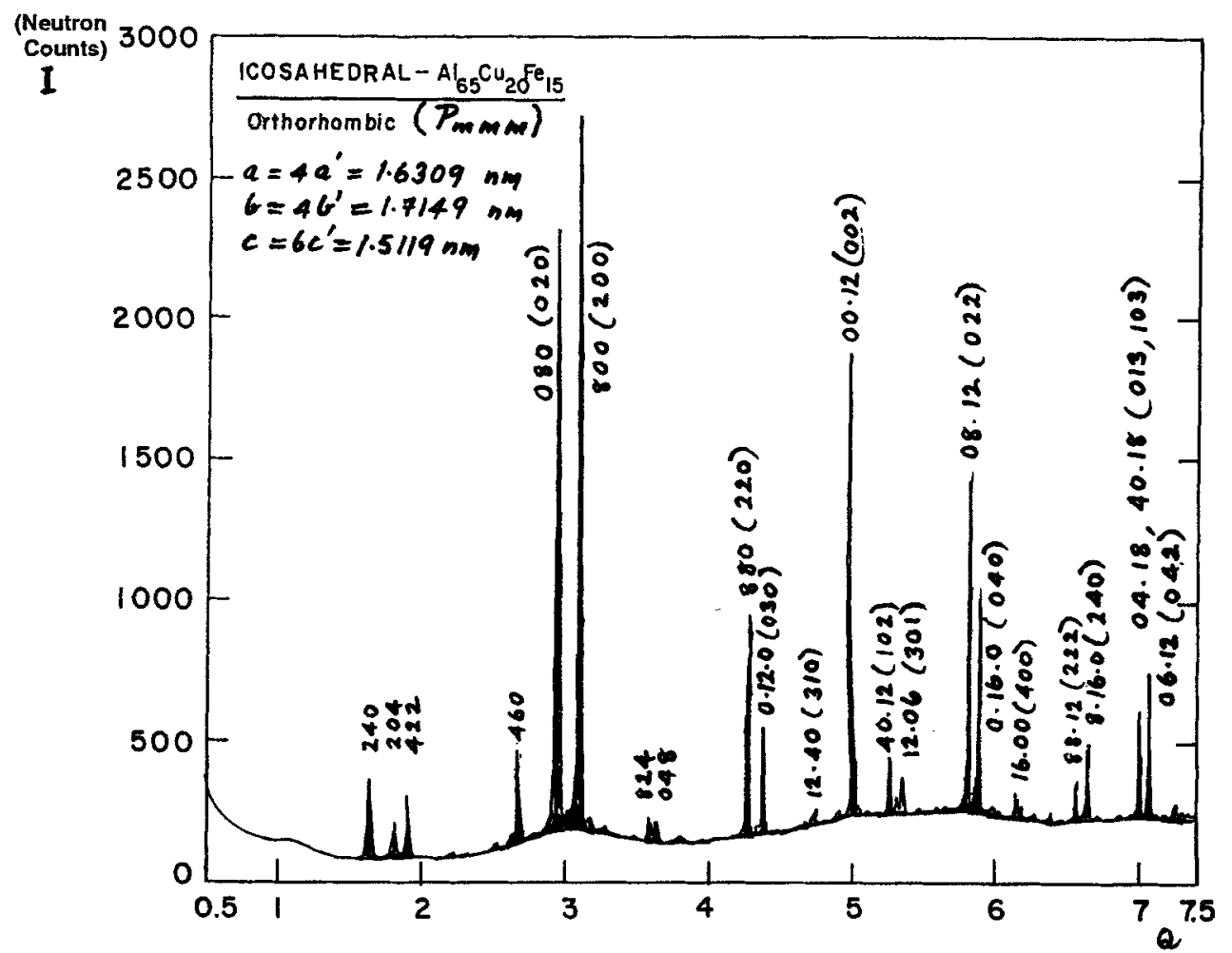

Figure 4. Neutron diffraction pattern from $\mathrm{Al}-\mathrm{Cu}-\mathrm{Fe}$ icosahedral phase. (Miller indices in brackets pertain to the basic orthorhombic cell.) 
Table 3. Comparison of calculated and observed interplaner distances $\left(d_{\text {cal }}\right.$ and $d_{\text {obs }}$ ) in nanometers and observed relative integrated intensities $\left(I_{\mathrm{obs}}\right)$ for Debye-Scherrer reflections from $\mathrm{Al}-\mathrm{Cu}-\mathrm{Fe}$ icosahedral phase. (Alloy composition; $\mathrm{Al}_{65} \mathrm{Cu}_{20} \mathrm{Fe}_{15}$ : orthorhombic unit cell dimensions; $a=1.6309, b=1.7149$, $c=1.5119$ : space group; $P_{m m m}$ (no. 47): orthorhombic basic cell dimensions; $a^{\prime}=0.4077, b^{\prime}=0.4287, c^{\prime}=0.2520$. Data on neutron diffraction from Grenoble, France. $I_{\mathrm{nbs}}$ rounded to integers with maximum of 100 for the strongest reflection).

\begin{tabular}{|c|c|c|c|c|c|}
\hline No. & $h k l$ & $h^{\prime} k^{\prime} l^{\prime}$ & $d_{\text {cal }}$ & $d_{\mathrm{obs}}$ & $I_{\mathrm{obs}}$ \\
\hline 1 & 200 & - & 0.815 & 0.815 & 4 \\
\hline 2 & 220,022 & - & $0.591,0.567$ & 0.582 & 10 \\
\hline 3 & 301 & - & 0.508 & 0.509 & 2 \\
\hline 4 & 103,222 & - & $0.482,0.466$ & 0.472 & $<1$ \\
\hline 5 & 330,411 & - & $0.394,0.384$ & 0.388 & 1 \\
\hline 6 & 240 & - & $0 \cdot 380$ & 0.382 & 11 \\
\hline 7 & 420 & - & $0 \cdot 368$ & 0.368 & $<1$ \\
\hline 8 & 402,024 & - & $0.359,0.346$ & 0.352 & $<1$ \\
\hline 9 & 204 & - & 0.343 & 0.347 & 5 \\
\hline 10 & 150,051 & - & $0.336,0.335$ & 0.335 & $<1$ \\
\hline 11 & 422 & - & 0.331 & 0.330 & 9 \\
\hline 12 & 440,350 & 110 & $0.295,0.290$ & 0.292 & $<1$ \\
\hline 13 & 053 & - & 0.284 & 0.284 & 1 \\
\hline 14 & 424 & - & $0 \cdot 264$ & 0.264 & $<1$ \\
\hline 15 & 361 & - & 0.249 & 0.249 & 1 \\
\hline 16 & 071,026 & - & $0.242,0 \cdot 242$ & 0.242 & $<1$ \\
\hline 17 & 206 & - & 0.240 & 0.239 & 2 \\
\hline 18 & 460 & - & $0 \cdot 234$ & 0.235 & 15 \\
\hline 19 & 363,552 & - & $0.226,0.226$ & 0.226 & 3 \\
\hline 20 & 046 & 011 & 0.217 & 0.217 & 3 \\
\hline 21 & 080,406 & 020,101 & $0.214,0.214$ & 0.214 & 83 \\
\hline 22 & 471,426 & - & $0.208,0.208$ & 0.208 & 3 \\
\hline 23 & 082,165 & - & $0.206,0.206$ & 0.206 & 4 \\
\hline 24 & 800 & 200 & 0.204 & 0.204 & 100 \\
\hline 25 & 464 & - & 0.199 & 0.199 & 2 \\
\hline 26 & 662,480 & 120 & $0 \cdot 191,0 \cdot 190$ & 0.191 & 1 \\
\hline 27 & 084 & - & 0.187 & $0 \cdot 187$ & $<1$ \\
\hline 28 & 840 & 210 & 0.184 & 0.185 & $<1$ \\
\hline 29 & 057 & - & 0.183 & 0.182 & $<1$ \\
\hline 30 & 626,507 & - & $0 \cdot 181,0 \cdot 180$ & 0.180 & 1 \\
\hline 31 & 804 & - & 0.179 & 0.179 & $<1$ \\
\hline 32 & 318 & - & $0 \cdot 178$ & 0.178 & $<1$ \\
\hline 33 & 824 & - & 0.176 & 0.176 & 3 \\
\hline 34 & 048 & - & $0 \cdot 173$ & 0.173 & 4 \\
\hline 35 & 408,903 & - & $0 \cdot 172,0 \cdot 171$ & $0 \cdot 171$ & $<1$ \\
\hline 36 & 646,484 & - & $0 \cdot 170,0 \cdot 170$ & $0 \cdot 170$ & $<1$ \\
\hline 37 & 457,385 & - & $0.167,0.167$ & $0 \cdot 167$ & $<1$ \\
\hline 38 & 853,844 & - & $0 \cdot 166,0 \cdot 166$ & 0.166 & 2 \\
\hline 39 & 806,068 & 201 & $0.159,0.158$ & 0.158 & $<1$ \\
\hline 40 & 268 & & 0.155 & $0 \cdot 155$ & $<1$ \\
\hline 41 & 846 & 211 & 0.1487 & 0.1488 & $<1$ \\
\hline 42 & 880 & 220 & 0.1477 & 0.1477 & 25 \\
\hline 43 & $648 \cdot 6 \cdot 10 \cdot 0$ & & $0 \cdot 1459,0 \cdot 1450$ & 0.1454 & 1 \\
\hline 44 & $0 \cdot 12 \cdot 0$ & 030 & 0.1429 & 0.1429 & 13 \\
\hline 45 & 619 & - & $0 \cdot 1424$ & 0.1424 & $<1$ \\
\hline 46 & $24 \cdot 10$ & - & 0.1405 & 0.1404 & $<1$ \\
\hline 47 & $4 \cdot 12 \cdot 0$ & 130 & 0.1349 & 0.1348 & 1 \\
\hline 48 & $7 \cdot 10 \cdot 3 \cdot 11 \cdot 05$ & - & $0.1332,0.1331$ & 0.1331 & 2 \\
\hline 49 & $12 \cdot 13 \cdot 10 \cdot 46$ & - & $0 \cdot 1308,0 \cdot 1304$ & 0.1307 & $<1$ \\
\hline 50 & 12.40 & 310 & 0.1296 & 0.1292 & $<1$ \\
\hline 51 & 389 & - & 0.1285 & 0.1285 & 1 \\
\hline 52 & $11 \cdot 54$ & - & $0 \cdot 1281$ & 0.1281 & $<1$ \\
\hline 53 & 839 & - & 0.1264 & 0.1267 & 1 \\
\hline 54 & $00 \cdot 12$ & 002 & 0.1260 & 0.1260 & 53 \\
\hline 55 & $0 \cdot 12 \cdot 6$ & 031 & 0.1243 & 0.1246 & 1 \\
\hline
\end{tabular}

\begin{tabular}{|c|c|c|c|c|c|}
\hline No. & $h k l$ & $h^{\prime} k^{\prime} l^{\prime}$ & $d_{\text {cal }}$ & $d_{\mathrm{obs}}$ & $I_{\mathrm{obs}}$ \\
\hline 56 & $10 \cdot 66$ & - & 0.1235 & 0.1235 & $<1$ \\
\hline 57 & 929 & - & $0 \cdot 1219$ & 0.1219 & $<1$ \\
\hline 58 & $11 \cdot 81$ & - & 0.1216 & 0.1215 & $<1$ \\
\hline 59 & $40 \cdot 12$ & 102 & 0.1204 & 0.1203 & $<1$ \\
\hline 60 & 12.06 & 301 & 0.1196 & 0.1196 & 7 \\
\hline 61 & $12 \cdot 26$ & - & $0 \cdot 1185$ & $0 \cdot 1184$ & 2 \\
\hline 62 & 13.50 & - & 0.1178 & 0.1178 & 5 \\
\hline 63 & $84 \cdot 10$ & - & 0.1168 & 0.1168 & $<1$ \\
\hline 64 & $06 \cdot 12$ & - & 0.1153 & 0.1153 & 1 \\
\hline 65 & $1 \cdot 15 \cdot 0$ & - & $0 \cdot 1141$ & $0 \cdot 1141$ & $<1$ \\
\hline 66 & $68 \cdot 10$ & - & 0.1125 & 0.1125 & 1 \\
\hline 67 & $09 \cdot 11$ & - & 0.1115 & 0.1115 & 1 \\
\hline 68 & $52 \cdot 13$ & - & $0 \cdot 1087$ & $0 \cdot 1088$ & 4 \\
\hline 69 & $08 \cdot 12$ & 022 & 0.1086 & $0 \cdot 1086$ & 31 \\
\hline 70 & $0 \cdot 16 \cdot 0 \cdot 80 \cdot 12$ & 040,202 & $0 \cdot 1072,0 \cdot 1072$ & $0 \cdot 1072$ & 27 \\
\hline 71 & $12 \cdot 86$ & 321 & 0.1045 & $0 \cdot 1044$ & 1 \\
\hline 72 & $16 \cdot 00$ & 400 & 0.1019 & $0 \cdot 1019$ & 2 \\
\hline 73 & $12 \cdot 12 \cdot 0$ & 330 & 0.0985 & 0.0985 & $<1$ \\
\hline 74 & $88 \cdot 12$ & 222 & 0.0959 & 0.0959 & 4 \\
\hline 75 & $8 \cdot 16 \cdot 0$ & 240 & 0.0949 & 0.0949 & 7 \\
\hline 76 & $12 \cdot 4 \cdot 12$ & 312 & 0.0903 & 0.0902 & $<1$ \\
\hline 77 & $4 \cdot 20 \cdot 0$ & 150 & 0.0839 & 0.0839 & 1 \\
\hline 78 & $04 \cdot 18$ & 013 & 0.0824 & 0.0824 & 9 \\
\hline 79 & $40 \cdot 18$ & 103 & 0.0823 & 0.0822 & 9 \\
\hline 80 & $0 \cdot 16 \cdot 12$ & 042 & 0.0816 & 0.0816 & 23 \\
\hline
\end{tabular}

contractions, and distortions taking place in the molten alloys, to fit the atoms of the icosahedral clusters into a Bravais lattice during the process of joining together with atom sharing, have been overlooked as these cannot be visualized and quantified precisely. In fact, the atomic coordinates of the basic cell (figure 3 ) are idealized and assigned, for convenience, exact values like $0.00,0.25$, 0.50 and 0.75 .

Considering the above facts and taking into account the ranges in interatomic distances between aluminium and the many transition metals involved in this study, as also the range in composition of the alloys, viz. 15 to 40 at of one or more transition metals, it is considered quite appropriate and wholly justifiable to suggest the following range for the parameters of the concerned basic orthorhombic cells:

$$
\begin{aligned}
& a^{\prime}=\mathbf{0 . 4 0 0} \pm 0.020 \mathrm{~nm}, \\
& b^{\prime}=\mathbf{0 . 4 2 0} \pm 0.020 \mathrm{~nm}, \text { and } \\
& c^{\prime}=\mathbf{0 . 2 5 0} \pm 0.012 \mathrm{~nm} .
\end{aligned}
$$

In the light of the model described above, all orthorhombic phases, i.e. quasicrystalline phases, complex crystalline phases, and crystalline approximants to quasicrystals, in Al-TM alloys containing 60-85 at\% Al should fall into a pattern where their lattice parameters $a, b$, and $c$ will work out to:

$$
a=m \cdot a^{\prime}, b=n \cdot b^{\prime}, \text { and } c=o \cdot c^{\prime},
$$

where $m, n$, and $o$ are integers. 
Table 4 features the results of an analysis of the lattice parameters of $36 \mathrm{Al}-\mathrm{TM}$ orthorhombic phases, for which reasonably reliable data, on composition as well, could be gathered, mostly from publications of the last decade. This analysis encompasses 10 crystalline phases, 7 quasicrystalline phases, and 19 rational approximants, mostly from ternary systems and occasionally featuring two or more such phases coexisting in the same specimen. In each case, the total number $(N)$ of basic cells making up the superstructure, and the concerned reference are also given.

\section{Discussion}

Before commenting on the results in table 4 , it is necessary to bear in mind that most of the data on rational approximants has been collected through electron diffraction studies only and hence cannot be considered very accurate. There is also appreciable scatter in the data from different laboratories. Furthermore, the chemical compositions and the formulae of the phases are tentative in many cases and therefore their reliability cannot be

Table 4. Analysis of orthorhombic phases in aluminium-transition metal alloys with 60 to 85 at $\%$ aluminium as superstructures of the basic cell proposed for icosahedral cluster compounds. $\left(a=m \cdot a^{\prime}, b=n \cdot b^{\prime}\right.$ and $c=o \cdot c^{\prime}$ where $a, b$, and $c$ are the lattice parameters of the concerned phase, $a^{\prime}, b^{\prime}$, and $c^{\prime}$ are the basic cell dimensions, all in nanometers, and $m, n$ and $o$ are integers. $N=m \cdot n \cdot o$, i.e. the total number of basic cells in the concerned phase).

\begin{tabular}{llllllllllllll}
\hline No. Alloy composition & A & $m$ & $a^{\prime}$ & B & $n$ & $b^{\prime}$ & $c$ & $o$ & $c^{\prime}$ & $N$ & Reference \\
\hline
\end{tabular}

I Crystalline phases

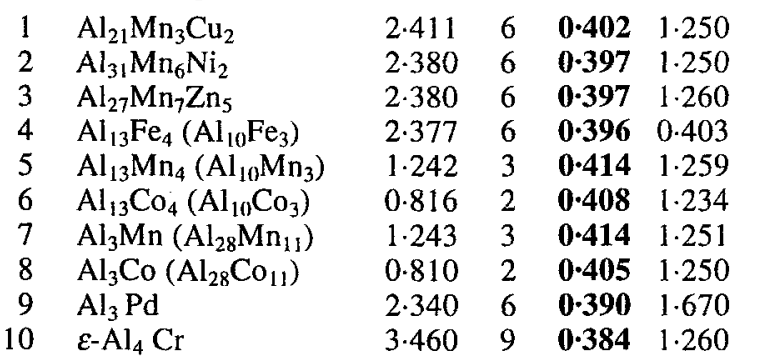

\begin{tabular}{|ll}
$\mathbf{0 . 4 1 7}$ & 0.772 \\
$\mathbf{0 . 4 1 7}$ & 0.755 \\
$\mathbf{0 . 4 2 0}$ & 0.778 \\
$\mathbf{0 . 4 0 3}$ & 0.775 \\
$\mathbf{0 . 4 2 0}$ & 1.479 \\
$\mathbf{0 . 4 1 1}$ & 1.445 \\
$\mathbf{0 . 4 1 7}$ & 1.483 \\
$\mathbf{0 . 4 1 7}$ & 1.250 \\
$\mathbf{0 . 4 1 8}$ & 1.230 \\
$\mathbf{0 . 4 2 0}$ & 2.000
\end{tabular}

$\begin{array}{rr}\mathbf{0} \cdot 257 & 54 \\ \mathbf{0} \cdot 252 & 54 \\ \mathbf{0} \cdot 259 & 54 \\ \mathbf{0} \cdot 258 & 18 \\ \mathbf{0} \cdot 247 & 54 \\ \mathbf{0} \cdot 241 & 36 \\ \mathbf{0 \cdot 2 4 7} & 54 \\ \mathbf{0} \cdot 250 & 30 \\ \mathbf{0 \cdot 2 4 6} & 120 \\ \mathbf{0 \cdot 2 5 0} & 216\end{array}$

54 Robinson (1952)

54 Robinson (1954)

54 Damjanovic (1961)

18 Ellner (1995)

54 Taylor (1960)

36 Burkhardt et al (1996)

$54 \quad$ Hiraga et al (1993)

Li et al (1994)

Ma et al (1990)

Wen et al (1992)

II Icosahedral ( $i-$ ) and decagonal $\left(d_{-}\right)$phases

$\begin{array}{ll}11 & i-\mathrm{Al}_{65} \mathrm{Cu}_{20} \mathrm{Ru}_{15} \\ 12 & i-\mathrm{Al}_{65} \mathrm{Cu}_{20} \mathrm{Fe}_{15} \\ 13 & i-\mathrm{Al}_{80} \mathrm{Mn}_{20} \\ 14 & i-\mathrm{Al}_{77} \mathrm{Mn}_{20} \mathrm{Si}_{3} \\ 15 & d-\mathrm{Al}_{65} \mathrm{Fe}_{20} \mathrm{Ni}_{15} \\ 16 & d-\mathrm{Al}_{65} \mathrm{Cu}_{20} \mathrm{Co}_{15} \\ 17 & d-\mathrm{Al}_{75} \mathrm{Mn}_{25}\end{array}$

$\begin{array}{lllll}1.626 & 4 & \mathbf{0 . 4 0 7} & 1.710 & 4 \\ 1.631 & 4 & \mathbf{0 . 4 0 8} & 1.715 & 4 \\ 1.655 & 4 & \mathbf{0 . 4 1 4} & 1.738 & 4 \\ 1.662 & 4 & \mathbf{0 . 4 1 6} & 1.747 & 4 \\ 1.662 & 4 & \mathbf{0 . 4 0 6} & 1.231 & 3 \\ 1.629 & 4 & \mathbf{0 . 4 0 7} & 1.240 & 3 \\ 1.642 & 4 & \mathbf{0 . 4 1 1} & 1.255 & 3\end{array}$

$\begin{array}{ll}\mathbf{0 . 4 2 8} & 1.508 \\ \mathbf{0 . 4 2 9} & 1.512 \\ \mathbf{0 . 4 3 5} & 1.529 \\ \mathbf{0 . 4 3 7} & 1.537 \\ \mathbf{0 . 4 1 0} & 1.502 \\ \mathbf{0 . 4 1 3} & 1.514 \\ \mathbf{0 . 4 1 8} & 1.526\end{array}$

$\begin{array}{ll}\mathbf{0} \cdot 251 & 96 \\ \mathbf{0} \cdot 252 & 96 \\ \mathbf{0} \cdot 255 & 96 \\ \mathbf{0} \cdot 256 & 96 \\ \mathbf{0} \cdot 250 & 72 \\ \mathbf{0 \cdot 2 5 2} & 72 \\ \mathbf{0} \cdot 254 & 72\end{array}$

Anantharaman (1994b)

96 Anantharaman (1994b)

96 Anantharaman (1989)

96 Anantharaman (1994b)

Anantharaman (1994b)

Anantharaman (1994b)

Anantharaman (1993)

III Rational approximants

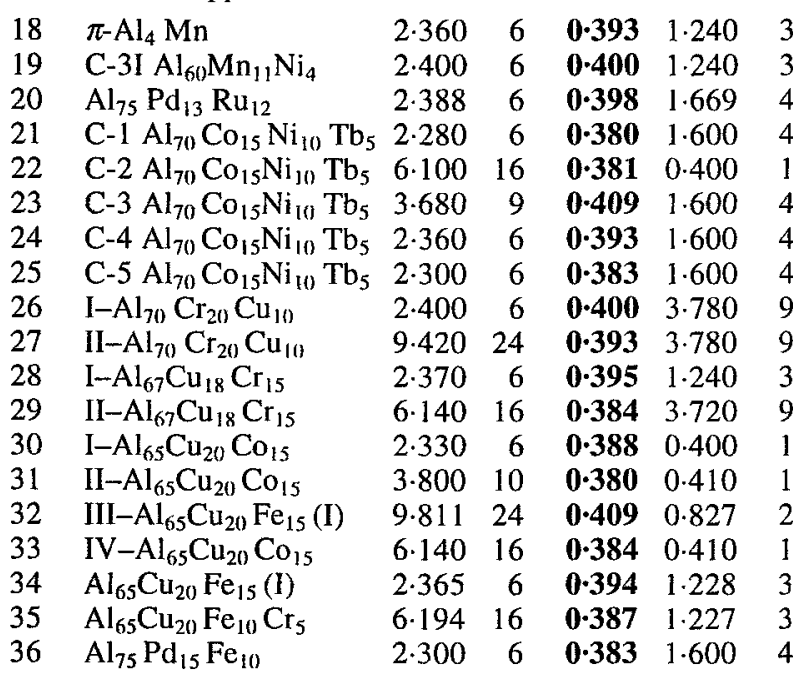

\begin{tabular}{|c|c|c|c|c|}
\hline 0.413 & 0.770 & 3 & 0.257 & \\
\hline 0.413 & 3.270 & 13 & 0.252 & 23 \\
\hline & & 13 & 0.252 & 31 \\
\hline 400 & 460 & 21 & $0 \cdot 260$ & \\
\hline 400 & 400 & 34 & $0 \cdot 247$ & \\
\hline $0 \cdot 400$ & .200 & 13 & $0 \cdot 246$ & 46 \\
\hline $0 \cdot 400$ & 2.000 & 8 & $0 \cdot 1$ & 19 \\
\hline 0.400 & $1 \cdot 260$ & 5 & $0 \cdot 1$ & 12 \\
\hline 0.420 & $3 \cdot 300$ & 13 & & 70 \\
\hline 0.420 & 2.040 & 8 & & 172 \\
\hline .413 & 0.780 & 3 & 0.2 & \\
\hline 413 & 1.970 & 8 & $0 \cdot 246$ & 115 \\
\hline 400 & 1.970 & 8 & 0.246 & \\
\hline 410 & 5.200 & 21 & $0 \cdot 248$ & \\
\hline .414 & 3.188 & 13 & $0 \cdot 2$ & \\
\hline .410 & 8.440 & 34 & 0.248 & 54 \\
\hline 409 & $3 \cdot 250$ & 13 & 0.250 & 23 \\
\hline 0.409 & 2.010 & 8 & $0 \cdot 251$ & \\
\hline 0.400 & 3.200 & 13 & 0.246 & \\
\hline
\end{tabular}

Li and Kuo (1991)

Van Tendeloo et al (1988)

Zhang et al (1995)

Yu et al (1993)

Yu et al (1993)

Yu et al (1994)

Yu et al (1994)

Yu et al (1994)

Okabe et al (1992)

Okabe et al (1992)

Wu et al (1996)

Wu et al (1996)

Liao et al (1992)

Liao et al (1992)

Launois et al (1990)

Launois et al (1990)

Dong et al (1992)

Dong et al (1992)

Edler et al (1998)

Observed

Range of $a^{\prime}$ Range of $b^{\prime}$ Range of $c^{\prime}$

\section{Proposed}

$0 \cdot 398 \pm 0 \cdot 018$

$0 \cdot 419 \pm 0 \cdot 019$

$0 \cdot 250 \pm 0 \cdot 010$ $\mathbf{0 . 4 0 0} \pm 0.020$ Observed values of $m: 2,3,4,6,9,10,16,24$

$\mathbf{0} \cdot \mathbf{4 2 0} \pm 0.020$ Observed values of $n: 1,2,3,4$,

$\mathbf{0 \cdot 2 5 0} \pm 0 \cdot 012$ Observed values of $o: 3,5,6,8,13,21,34$ 
vouched for. There also seems to be lack of unanimity on the sequence of the three lattice parameters $a, b$, and $c$ of the orthorhombic phases. All the same, it is extremely gratifying that the following range of basic cell parameters emerges from a study of no less than 36 orthorhombic phases in Al-TM alloys containing $60-85$ at $\% \mathrm{Al}$ and often more than one transition metal in the chosen range of $15-40$ at\% TM, and also featuring three different categories of intermetallic phases:

$$
\begin{aligned}
& a^{\prime}=\mathbf{0 . 3 9 8} \pm 0.018 \mathrm{~nm}, \\
& b^{\prime}=\mathbf{0 . 4 1 9} \pm 0.019 \mathrm{~nm}, \text { and } \\
& c^{\prime}=\mathbf{0 . 2 5 0} \pm 0.010 \mathrm{~nm} .
\end{aligned}
$$

The mean values here are astonishingly close to the mean values of $0.400,0.420$, and $0.250 \mathrm{~nm}$, suggested earlier on the basis of the model developed for this type of icosahedral cluster compounds.

The actual values of $m, n$, and $o$ however seem to suggest considerable complexity and variety in the ordering process, involving large numbers of $\mathrm{Al}$ atoms, TM atoms, and vacancies in these orthorhombic phases. The impact of the Fibonacci series of numbers, viz. 1, 2, 3, 5, $8,13,21,34$ etc has been stressed by many investigators (see Kuo 1994) in relation to the observed lattice parameters of approximant phases. In the present analysis, only the values of $o$ related to the $c$ parameter, viz. $3,5,6$, $8,13,21$, and 34, suggest any role for the Fibonacci series, even though the significance of this role is as yet far from clear. As for the many values of $n$ : viz. 1, 2, 3, 4, and 9; and of $m$ : viz. $2,3,4,6,9,10,16$, and 24 , it is again difficult to draw any meaningful inference from them at this stage.

It is worth mentioning here that the lattice parameters computed for icosahedral and decagonal phases depend heavily on the detection of weak low-angle X-ray/neutron reflections, and may turn out to be different and larger in value if very accurate recording based on more sophisticated instrumentation reveals more such reflections. However, such a revision of the lattice parameters may not have any impact on the $a^{\prime}, b^{\prime}$, and $c^{\prime}$ values arrived at, even though the values of $m, n$, and $o$ may well prove to be different.

The number of basic cells $(N)$, making up the orthorhombic superstructures, also displays a great variety; but falls into two major groups. The smallest value is 18 and nearly half the values are divisible by 18 , viz. 36, 54, 72, 216, 234, 468, 504, 702, 1152 and 1728 . It is tempting to conclude that 18 units with 54 atoms constitute one of the basic superstructures for such orthorhombic Al-TM phases. Incidentally, such a hyperatom with 54 atoms was postulated quite some time ago (Mackay 1962) and has been frequently referred to as the Mackay Icosahedron in quasicrystallographic literature. Another basic value is 24 , and again nearly half the values are divisible by this number, viz. $48,72,96,120,192$, $216,312,384,504,624,1152$, and 1728.
In an earlier part of this paper, the effective number of atoms in the basic cell was proposed as 3 , and computed as very close to 3 in case of the $\mathrm{Al}-\mathrm{Cu}-\mathrm{Fe}$ icosahedral phase. Examining those crystalline phrases listed in table 4 , which are made up of 54 basic cells in this analysis, it is highly significant that the unit cell in most of these cases has been assigned 156 atoms on the basis of X-ray crystallographic studies. The latter leads to a value of 2.89 atoms per basic cell. This inference is also strongly in favour of the concepts underlying the present study.

In conclusion, the author would like to stress that the above results are preliminary and tentative, even though quite significant and supportive from the point of view of the proposed models for icosahedral cluster compounds. These should now be compared with the results from similar concepts underlying clusters or hyperatoms of bigger sizes like the I-3 cluster of 36 atoms (Kreiner and Franzen 1997), the I-5 cluster of Mackay Icosahedron of 54 atoms (Mackay 1962) and the I-12 cluster of 81 atoms associated with the Frank-Kasper phases (Shoemaker and Shoemaker 1988), all of which start with individual icosahedral atomic clusters in the concerned alloy melts.

\section{Acknowledgements}

It is a pleasure and privilege for the author to acknowledge the inspiration he received in this study, as also in his earlier ones on quasicrystals and metallic glasses in aluminium alloys, from the work and methodology of the late Professor W Hume-Rothery, in whose laboratories at Oxford University he pursued his doctoral researches during 1951-1954 as a Rhodes Scholar from India and got initiated into the magic and mystery underlying structure, structural changes and structural irregularities in the world of metals and alloys.

\section{References}

Anantharaman T R 1987 Mater. Sci. Forum 22-24 55

Anantharaman T R 1989 Curr. Sci. 581067

Anantharaman T R 1993 Scr. Met. Mater. 281555

Anantharaman T R 1994a Bull. Mater. Sci. 17717

Anantharaman T R $1994 \mathrm{~b}$ in Experimental methods of phase diagram determination (eds) J E Morral, $R$ S Schiffman and S M Merchant (USA: TMS) p 173

Anantharaman T R 1998a Curr. Sci. 7531

Anantharaman T R 1998b Bull. Mater. Sci. 2771

Anantharaman T R, Ramachandrarao P, Suryanarayana C, Lele S and Chattopadhyay K 1977 Trans. Indian Inst. Met. 30423 and 434

Bernal J D 1959 Nature 183141

Burkhardt U, Ellner M and Grin Y 1996 Powder Diffraction 11 123

Calvayrac Y, Quivy A, Bessiere M, Lefebvre S, CornierQuiqundon M and Gratias D 1990 J. Phys. France 51417 
Chidambaram R, Sanyal M K, Raghunathan V S, Nambissan P M G and Sen P 1993 Phys. Rev. B48 128

Damjanovic A 1961 Acta Cryst. 141982

Dong C and Dubois J M 1991 Phase Trans. 32119

Dong C, Dubois J M, Kang S S and Audier M 1992 Philos. Mag. B65 107

Edler F J, Estermann A, Haibach T and Steurer W 1998 (preprint)

Ellner M 1995 Acta Cryst. B51 31

Frank F C 1952 Proc. R. Soc. London A215 43

Gong X G and Kumar V 1995 Proceedings of the international conference on quasicrystals (eds) C Janot and R Mosseri (Singapore: World Scientific) p 484

Hiraga K, Kaneko M, Matsuo Y and Hashimoto S 1993 Philos. Mag. B67 193

Hume-Rothery W and Anderson E 1960 Philos. Mag. 5383

Kreiner G and Franzen H F 1995 J. Alloys Comp. 22115

Kreiner G and Franzen H F 1997 J. Alloys Comp. 26183

Kuo K H 1994 Mater. Chem. and Phys. 391

Kuo K H 1998 (private communication)

Kuo K H and Zhang Z 1997 Prog. Cryst. Growth Charact. 34 191

Launois P, Audier M, Denoyer F, Dong C, Dubois J M and Lambert M 1990 Europhys. Lett. 13629

Li X Z and Kuo K H 1991 Philos. Mag. B66 117

Li X Z, Ma X L and Kuo K H 1994 Philos. Mag. Lett. 70221

Liao X Z, Kuo K H, Zhang H and Urban K 1992 Philos. Mag. B66 549

Ma X L and Kuo K H 1992 Metall. Trans. A23 1121

Ma L N, Wang R and Kuo K H 1990 J. Less-Common Metals 16337

Mackay A L 1962 Acta Cryst. 15916
Niizeki K 1992 J. Phys A: Math. Gen. 251843

Okabe T, Furihata J I, Morishita K and Fujimori H 1992 Philos. Mag. Lett. 66259

Pauling L 1947 J. Am. Chem. Sci. 69542

Ranganathan S and Chattopadhyay K 1989 Phase Trans. 1667

Robinson K 1952 Philos. Mag. 43775

Robinson K 1954 Acta Cryst. 7494

Ryba E, Song S and Wang L 1993 J. Non-Cryst. Solids 153623

Schechtman D, Blech I, Gratias D and Cahn J W 1984 Phys. Rev. Lett. 531951

Shi N C, Li X Z, Ma Z S and Kuo K H 1994 Acta Cryst. B50 22

Shoemaker D P and Shoemaker L B 1988 Introduction to quasicrystals (ed.) M V Jaric (Academic Press Inc.) p 1

Steurer W 1996 Physical metallurgy (eds) R W Cahn and P Haasen (Elsevier Science) p 372

Steurer W 1998 (private communication)

Sui H N, Sun K and Kuo K H 1997 Philos. Mag. 75379

Taylor M A 1960 Acta Metall. 8256

Van Tendeloo G, Van Landuyt I, Amelinkx S and Ranganathan S 1988 J. Microsc. 1491

Van Tendeloo G, Alok Singh and Ranganathan S 1991 Philos. Mag. A64 413

Wen K Y, Chen Y L and Kuo K H 1992 Met. Trans. A23 2437

Widom M 1987 Non-linearity in condensed matter (eds) A R Bishop et al (Berlin: Springer) p 130

Wu J S, Ma X L and Kuo K H 1996 Philos. Mag. Lett. 73163

Yu R C, Li X Z, Xu D P, Zhang Z, Su W H and Kuo K H 1993 Philos. Mag. Lett. 67287

Yu R C, Li X Z, Xu D P, Zhang Z, Su W H and Kuo K H 1994 Scr. Met. Mater. 311285

Zhang B, Li X Z, Steurer W, Schneider J and Frey F 1995 Philos. Mag. Lett. 72239 